\title{
Oral tuberculosis
}

\author{
D. P. Von Arx, ' and A. Husain, ${ }^{2}$
}

\section{Although rare, doctors and dentists should be aware of the possible occurrence of oral lesions of tuberculosis and consider them in the differential diagnosis of suspicious oral ulcers.}

\begin{abstract}
Tuberculosis is a major cause of ill health 1 and death worldwide, but has been declining in incidence in industrialised countries until recently. A steady decline in the numbers of tuberculosis notifications in England and Wales ceased in the mid-1980s and increases were seen in the late 1980s and early 1990 s. $^{1}$

The clinical presentation of tuberculosis may take many forms. However, with the decline in numbers, tuberculous lesions of the oral cavity have become so rare that they are frequently overlooked in the differential diagnosis of oral lesions.
\end{abstract}

\section{Case Report}

A 36-year-old lady was referred to the maxillofacial unit for assessment of a non-healing ulcer of the right buccal mucosa.

She had first noticed the lesion 4 months ago and it had failed to heal despite the administration of antibiotics and other topical mouthwashes. It had slowly enlarged and was painful, eventually restricting her to a soft diet. She had also noticed increasing hoarseness for the last 2 months and had felt generally unwell and lethargic for 2 years. She had suffered with a constant cough for 10 months, producing yellow sputum. During this period she had suffered one episode of haemoptysis for which she had not sought medical advice and had also noticed some weight loss.

On examination, she appeared pale and generally unwell. She had an ulcerated

${ }^{1 *}$ Specialist Registrar ${ }^{2}$ Senior House Officer, Maxillofacial Unit, Kent \& Canterbury Hospital,

Ethelbert Road, Canterbury, Kent CT1 3NG

${ }^{*}$ Correspondence to: D P Von Arx

email:derekvonarx@66sisters.freeserve.co.uk

REFEREED PAPER

Received 06.07.00; Accepted 12.10.00

(C) British Dental Journal 2001; 190: 420-422

\section{In brief \\ - The incidence of tuberculosis is once again on the increase in the UK \\ - Multidrug resistant strains of Mycobacterium tuberculosis are emerging \\ - Tuberculosis should always be considered as a possible cause of chronic oral ulceration}

lesion of the right buccal mucosa at the right commissure of her mouth (Fig. 1). It measured $3 \mathrm{~cm}$ by $1 \mathrm{~cm}$ with a shallow ulcerated base surrounded by rolled margins. There was also a superficial ulcer, $0.5 \mathrm{~cm}$ in diameter, on the soft palate, to the right of the midline. There were also several small cervical lymph nodes palpable.

It was felt that there was a strong possibility that the lesion was malignant, possibly a squamous cell carcinoma, and so an urgent incisional biopsy was performed under local anaesthesia.

Histological examination showed inflamed ulceration of the buccal mucosa with several granulomas involving the underly- ing submucosal tissue and muscle. Some granulomas were sarcoid-like and numerous giant cells were identified, some of the Langhans type. This raised the possibility of granulomatous infection, including tuberculous or fungal infection, or a diagnosis of sarcoid.

Subsequent stains for fungi (PAS and Grocott Silver) and bacteria (Gram stain) were negative. However several acid-fast bacilli were identified with a Ziehl-Neelsen stain, situated within the granulomas, consistent with tuberculous granulomatous infection.

Blood tests were within normal limits except for a raised white cell count $\left(12.3 \times 10^{9}\right)$, a raised erythrocyte sedimentation rate $(96 \mathrm{~mm} / \mathrm{hour})$ and a raised Creactive protein $(77.6 \mathrm{mg} / \mathrm{L})$. A serum angiotensin converting enzyme level was not raised (35 IU/L, normal range 8-52). In view of these findings a chest $\mathrm{x}$-ray was obtained that showed bilateral upper lobe consolidation and cavitation, consistent with pulmonary tuberculosis (Fig. 2).

A diagnosis of pulmonary tuberculosis was confirmed by the culture of Mycobacterium tuberculosis from sputum samples. She was started on medical treatment of Rifampicin, Isoniazid and Pyrazinamide immediately and her further management undertaken by a respiratory physician.

Her condition rapidly improved with complete resolution of her oral lesion and her voice returned to normal. Direct laryn-
Fig. I $3 \times$ I cm² ulcer of the right buccal mucosa

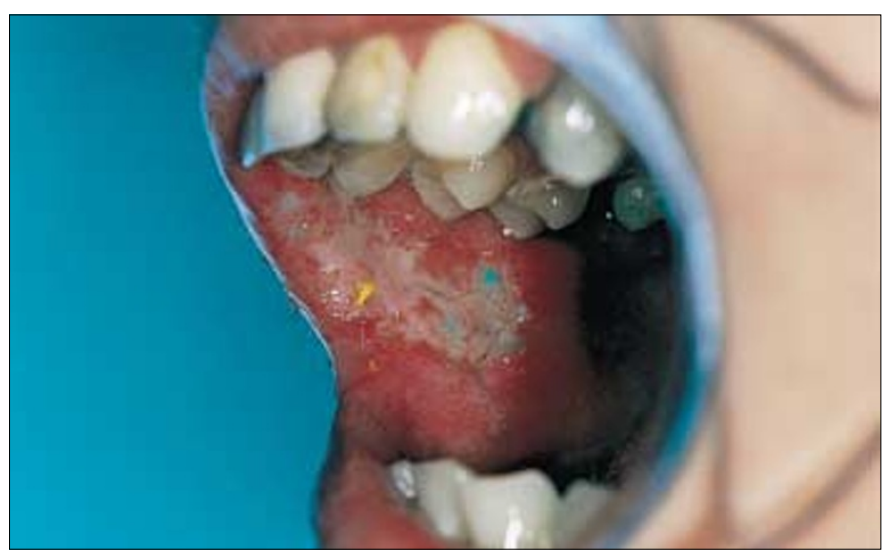


goscopy at this time confirmed the absence of any tuberculous lesion of the larynx. Her productive cough and general malaise both improved.

Further investigation of her family history revealed that her brother-in-law was treated for tuberculosis 15 years previously and that his brother was under current treatment for the same condition. It would seem that the brother-in-law was the index case, as the patient had had no contact with her brother for at least 10 years. Contact tracing of her family was undertaken, following the protocol laid down by the Joint Tuberculosis Committee of the British Thoracic Society. ${ }^{2}$

\section{Discussion}

During most of the last century the incidence of tuberculosis in the industrialised nations has steadily declined. There are numerous reasons for this including, improvements in public health and nutritional status, the widespread use of bacille Calmette-Guerin (BCG) vaccine in schoolchildren and improved anti-tuberculous chemotherapy.

The more recent increase in tuberculosis in the UK has been attributed to increases in minority groups such as immigrants of African and Indian subcontinent ethnic origin, ${ }^{3,4}$ rather than any increase seen in the indigenous population. Increasing problems with tuberculosis may well continue because of the continuing emergence of multidrug resistant strains of M. tuberculosis, ${ }^{5}$ which is a major threat, particularly to those with HIV infection and AIDS, in whom the mortality rates are high.

Also, at a time of increasing incidence of tuberculosis, many local authorities are withdrawing, or considering withdrawing, the BCG vaccine previously given to all schoolchildren in the UK. Problems with manufacturers supplying the vaccine are also being encountered at this time, with an inadequate supply of the vaccine being produced.

Although oral tuberculosis has been well documented, tuberculous lesions of the upper aerodigestive tract have become rare. Tuberculous lesions of the mouth may be
Fig. 2 Postero-anterior chest radiograph showing bilateral upper lobe consolidation and cavitation, consistent with pulmonary tuberculosis

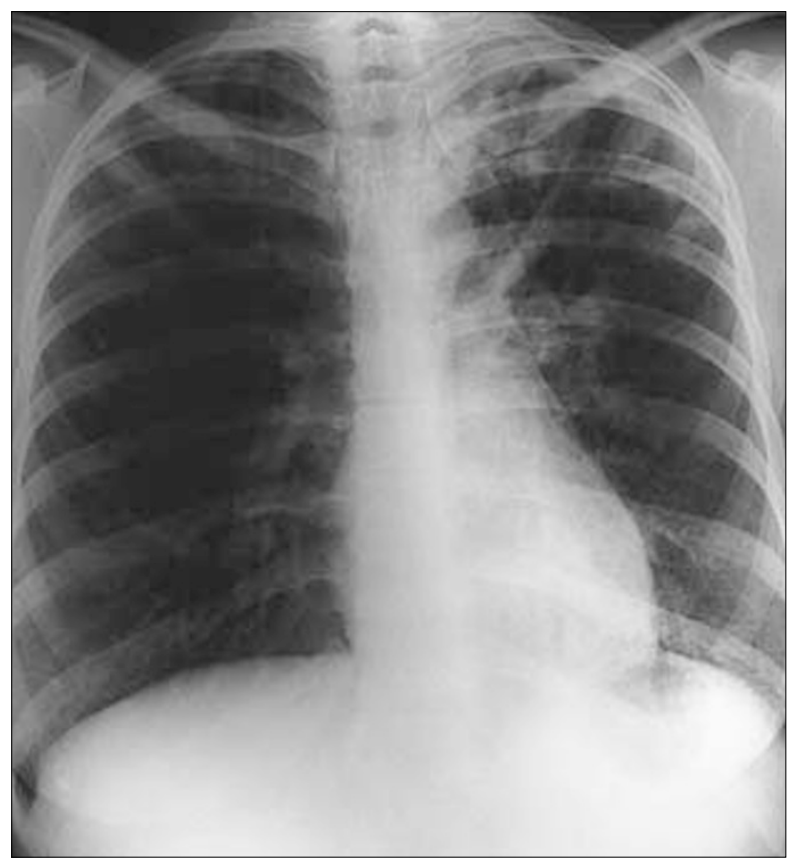

either primary, or secondary to pulmonary tuberculosis, ${ }^{6}$ with secondary lesions being more common. The typical oral lesions consist of a stellate ulcer, most commonly on the dorsum of the tongue. The ulcer may have undermined edges and a granulating floor although the clinical picture is variable. The ulcer may be ragged and indurated and is often painful.

Although the tongue is the commonest site for oral tuberculous lesions, ${ }^{7,8}$ they may also occur on the gingiva, floor of mouth, palate, lips and buccal mucosa. ${ }^{9}$ Tuberculosis of the tongue has also presented as macroglossia. ${ }^{10}$ It may also be present around the upper aerodigestive tract as parotitis, ${ }^{11,12}$ intra-osseous lesions, ${ }^{13,14}$ preauricular swelling and trismus, ${ }^{15}$ tracheitis $^{16}$ and laryngitis (as in the case reported).

The differential diagnosis of a tuberculous ulcer of the oral cavity includes aphthous ulcers, traumatic ulcers, syphilitic ulcers and malignancy, including primary squamous cell carcinoma, lymphoma and metastases. As reported here, the most likely clinical diagnosis is that of squamous cell carcinoma, in which case biopsy is mandatory. It is most likely that tuberculosis is only considered when the histological specimen reveals a granulomatous lesion. This would then lead to consideration of other orofacial granulomatous conditions such as sarcoid, Crohn's disease, the deep mycoses, cat-scratch disease, foreign-body reactions, tertiary syphilis and Melkersson-Rosenthal syndrome.

The diagnosis of tuberculosis is confirmed by the presence of acid-fast bacilli in the specimen, or more likely by culture of tuberculous bacilli. Since oral tuberculosis is almost always secondary to pulmonary tuberculosis, sputum culture must also be carried out. Radiographic evidence of tuberculosis must also be sought.

As stated, contact tracing follows the protocol of the Joint Tuberculosis Committee of the British Thoracic Society. For patients with pulmonary tuberculosis, close contacts are those sharing a house, and are most at risk. Occasionally a contact at work is close enough to be equivalent to a household contact. Casual contacts are most occupational contacts and need only be examined if they are unusually susceptible to infection, such as immunocompromised adults. Investigation of contacts may include Heaf testing and chest radiography.

All staff in regular contact with patients 
are at potential risk of contracting tuberculosis. However, evidence from the 1980s suggested that the incidence of tuberculosis in health care workers was no higher than in the general population. ${ }^{17}$ All health care workers at risk should be protected by BCG vaccination. Pre-employment screening should be carried out, with details of previous BCG vaccination obtained, and the presence or absence of a BCG scar noted. A Heaf test is only necessary in the absence of a BCG scar.

Although occupational infection is uncommon, an outbreak of oral tuberculosis following dental treatment at two clinics has been reported. ${ }^{18}$ The dentist who worked at both clinics was found to have pulmonary tuberculosis and, presumably, was the source of infection.

In conclusion, tuberculosis of the oral cavity is relatively rare and has largely become a forgotten diagnosis of oral lesions. However, with the recent reversal in the incidence of tuberculosis, it should always be included in the differential diagnosis of oral ulceration, as delay in diagnosis may have serious consequences.
The authors would like to thank Mr N Bradley, Consultant maxillofacial surgeon, for permission to report this case.

1 Anonymous. National survey of tuberculosis in England and Wales 1998. Communicable Disease Report. CDR Weekly 1998; 8: 209-212.

2 Joint Tuberculosis Committee of the British Thoracic Society. Control and prevention of tuberculosis in the United Kingdom: Code of practice 1994. Thorax 1994; 49: 1193-1200.

3 Kumar D, Watson J M, Charlett A, Nicholas S, Darbyshire J H (on behalf of a Public Health Laboratory Service/British Thoracic Society/ Department of Health Collaborative Group) Tuberculosis in England and Wales in 1993: results of a national survey. Thorax 1997; 52. 1060-1067.

4 Ormerod P, Charlett A, Gilham C, Darbyshire $\mathrm{J} \mathrm{H}$, Watson J. Geographical distribution of tuberculosis notifications in national surveys of England and Wales in 1988 and 1993: report of the Public Health Laboratory Service/British Thoracic Society/Department of Health Collaborative Group. Thorax 1998; 53: 176181.

5 Snider D E, Castro K G. The global threat of drug-resistant tuberculosis. New England J Med 1998; 338: 1689-1690.

6 Eng H L, Lu S Y, Yang C H, Chen W J. Oral tuberculosis. Oral Surgery, Oral Medicine, Oral Pathology, Oral Radiology, \& Endodontics 1996; 81: 415-420.

7 Jawad J, El-Zuebi F. Primary lingual tuberculosis: a case report. J Laryngol Otol 1996; 110: 177-178.
8 Gupta A, Shinde K J, Bhardwaj I. Primary lingual tuberculosis: a case report. J Laryngol Otol 1998; 112: 86-87.

9 Hathiram B T, Grewal D S, Irani D K, Tankwal P M, Patankar M. Tuberculoma of the cheek: a case report. Primary lingual tuberculosis: a case report. J Laryngol Otol 1997; 111: 872-873.

10 Ramesh V. Tuberculoma of the tongue presenting as macroglossia. Cutis 1997; 60 : 201-202.

11 Bhat N A, Stansbie J M. Tuberculous parotitis: a case report. J Laryngol Otol 1996; 110: 976977.

12 Suoglu Y, Erdamar B, Katircioglu OS, Cevikbas U. Tuberculosis of the parotid gland. J Laryngol Otol 1998; 112: 588-591.

13 Kothari P, Bartella L, Carter J, Chan O, Piper K. Tuberculosis of the mandible in a child. $J$ Laryngol Otol 1998; 112: 585-587.

14 Gal G, Kaplan I, Calderon S, Carlson E R. Large perimandibular swelling. J Oral Maxillofac Surg 1997; 55: 1134-1143.

15 Ruggiero S L, Hilton E, Braun T W. Trismus and preauricular swelling in a 20 -year-old black woman. J Oral Maxillofac Surg 1996; 54: 1234-1239.

16 Tong F M, Chow S K. Primary tuberculous tracheitis. J Laryngol Otol 1998; 112: 579-580.

17 Lunn J A, Mayho V. Incidence of pulmonary tuberculosis by occupation of hospital employees in the National Health Service in England and Wales 1980-84. J Society of Occupational Med 1989; 39: 30-32.

18 Smith W H R, Davis D, Mason K D, Onions J P. Intraoral and pulmonary tuberculosis following dental manipulation. Lancet 1982; 1 : 842-843. 